\title{
Successful use of angiotensin II for vasoplegia after thoracoabdominal aortic aneurysm repair
}

Subhasis Chatterjee, MD, ${ }^{\mathrm{a}, \mathrm{b}, \mathrm{c}}$ Ourania Preventza, MD, ${ }^{\mathrm{b}, \mathrm{c}, \mathrm{d}}$ Mariam C. Mousavi, PharmD, ${ }^{\mathrm{e}}$ Vicente Orozco-Sevilla, MD, ${ }^{\mathrm{b}, \mathrm{d}, \mathrm{d}}$ Scott A. LeMaire, MD, ${ }^{\mathrm{b}, \mathrm{d}, \mathrm{f} f \mathrm{f}}$ and Joseph S. Coselli, MD, ${ }^{\mathrm{b}, \mathrm{c}, \mathrm{d}}$ Houston, Tex

From the ${ }^{\mathrm{a} D i v i s i o n}$ of General Surgery, ${ }^{\mathrm{b}}$ Division of Cardiothoracic Surgery, and ${ }^{\mathrm{f}}$ Office of Surgical Research, Michael E. DeBakey Department of Surgery, Baylor College of Medicine, Houston, Tex; Departments of ${ }^{\mathrm{c} C}$ Cardiovascular Surgery and ${ }^{\mathrm{e}}$ Pharmacy, CHI St Luke's Health-Baylor St Luke's Medical Center, Houston, Tex; and ${ }^{\mathrm{d}}$ Department of Cardiovascular Surgery, Texas Heart Institute, Houston, Tex.

S.A.L.'s work is supported in part by the Jimmy and Roberta Howell Professorship in Cardiovascular Surgery at Baylor College of Medicine.

Disclosures: Dr Coselli participates in clinical trials with Bolton Medical; consults for and participates in clinical trials with Medtronic and W. L. Gore \& Associates; and consults for, participates in clinical trials with, and receives royalties and grant support from Terumo Aortic. Dr LeMaire serves as a consultant for Terumo Aortic and Baxter Healthcare; serves as a principal investigator for clinical studies sponsored by Terumo Aortic and CytoSorbants; and serves as a co-investigator for clinical studies sponsored by W. L. Gore \& Associates. Dr Preventza consults for and participates in clinical trials with Medtronic and W. L. Gore \& Associates. All other authors reported no conflicts of interest.

The Journal policy requires editors and reviewers to disclose conflicts of interest and to decline handling or reviewing manuscripts for which they may have a conflict of interest. The editors and reviewers of this article have no conflicts of interest.

Received for publication July 31, 2020; revisions received July 31, 2020; accepted for publication Aug 10, 2020; available ahead of print Aug 15, 2020.

Address for reprints: Subhasis Chatterjee, MD, Divisions of General Surgery \& Cardiothoracic Surgery, Department of Surgery, Baylor College of Medicine, One Baylor Plaza, MS: BCM 390, Houston, TX 77030 (E-mail: Subhasis.Chatterjee@bcm.edu).

JTCVS Techniques 2020;4:72-5

2666-2507

Copyright (C 2020 The Authors. Published by Elsevier Inc. on behalf of The American Association for Thoracic Surgery. This is an open access article under the CC BY-NC-ND license (http://creativecommons.org/licenses/bync-nd/4.0/).

https://doi.org/10.1016/j.xjtc.2020.08.007

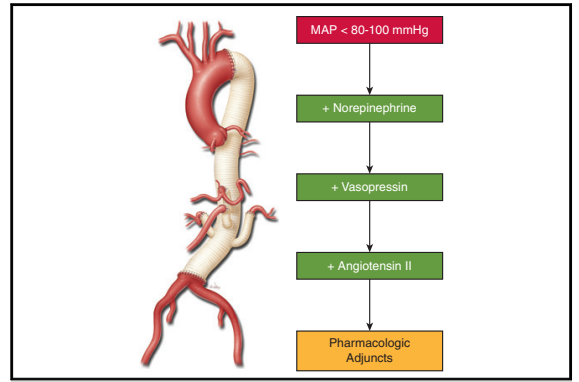

Vasoplegia management plan with vasopressors and adjuncts. MAP, Mean arterial pressure.

CENTRAL MESSAGE

Vasoplegia, or vasoplegic shock, risks spinal cord ischemia after thoracoabdominal aortic aneurysm repair. We report on the successful use of angiotensin ॥ to prevent spinal cord deficit.

See Commentaries on pages 76 and 77.
Video clip is available online.

Vasoplegic shock, or vasoplegia, features refractory hypotension, high cardiac output, and low systemic vascular resistance. Typically, for patients who undergo thoracoabdominal aortic aneurysm repair (TAAAR), fluids and vasopressors are used to maintain a target mean arterial pressure (MAP) of 80 to $100 \mathrm{~mm} \mathrm{Hg}$ to prevent spinal cord ischemia. Spinal cord deficit (SCD) is among the most feared complications after Crawford extent II TAAAR, with an incidence of approximately $8 \% .{ }^{1}$ We describe a novel case in which angiotensin II (AngII; Giapreza, La Jolla Pharmaceutical Company; San Diego, Calif) was used to treat vasoplegia after TAAAR to maintain a satisfactory MAP and prevent SCD.

\section{CASE REPORT}

A 61-year-old man with an extensive aortic surgical history presented with a symptomatic 10.2-cm Crawford extent II TAAA. He had previously undergone endovascular repair of an infrarenal abdominal aortic aneurysm and an ascending aortic and hemiarch repair with an aortic root bioprosthetic replacement (29-mm Medtronic Freestyle; Minneapolis, Minn) for an acute DeBakey type I aortic dissection. His medical history was also notable for moderate left ventricular dysfunction (left ventricular ejection fraction, $35 \%$ ) and stage 2 chronic kidney disease with an atrophic right kidney (serum creatinine level, $0.9 \mathrm{~g} / \mathrm{dL}$ ). The patient was taking beta blockers but not renin-angiotensin-aldosterone system inhibitors. He was taken to surgery with a MAP of $81 \mathrm{~mm} \mathrm{Hg}$. He provided written informed consent to participate in our institutional review board-approved protocol, allowing us to report his case and include it in research studies.

With cerebrospinal fluid drainage and left heart bypass, a Crawford extent II TAAAR was performed, including patch reimplantation of the T8 intercostal arteries and bypasses to 


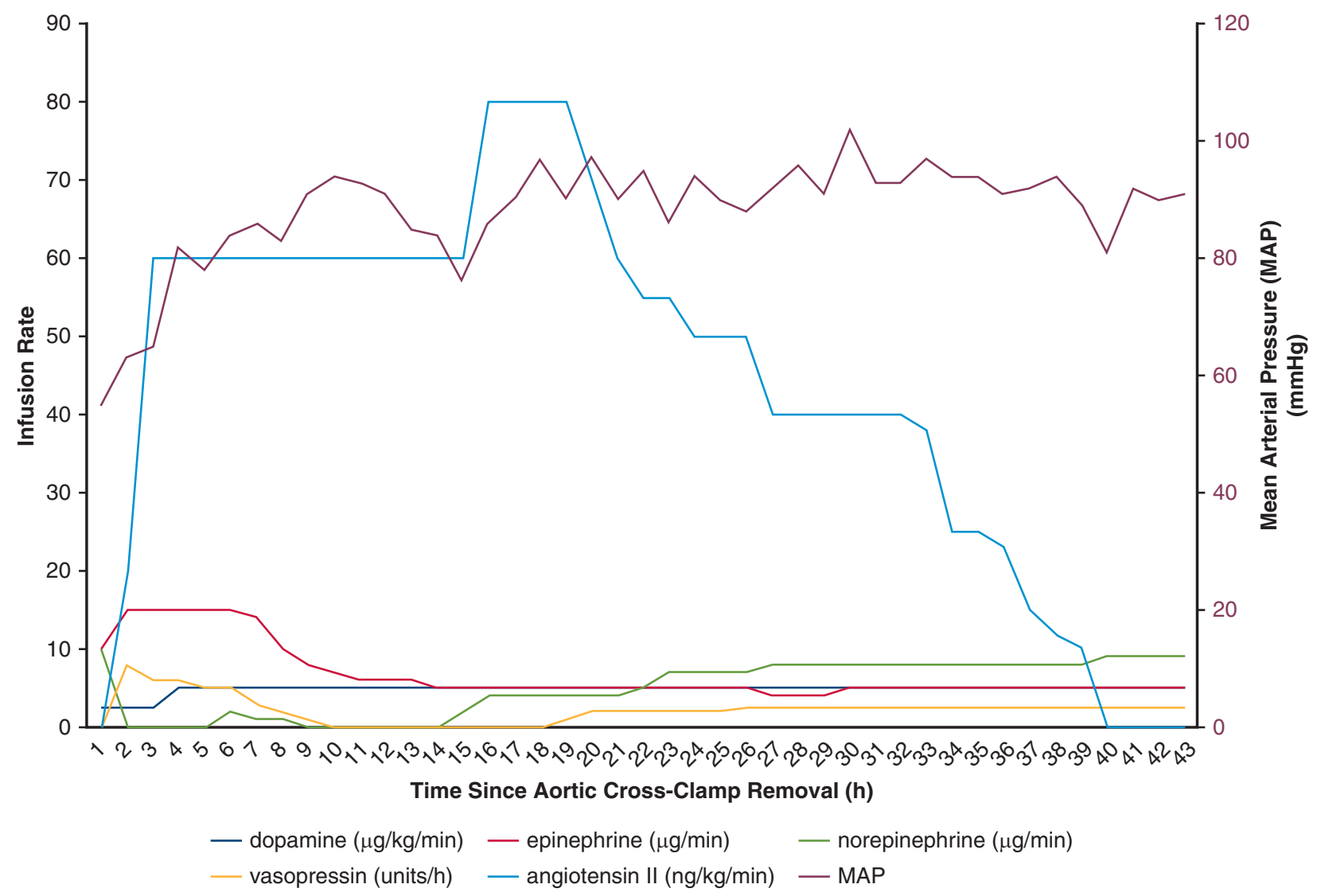

FIGURE 1. Time course of vasoactive medication administration. Five different vasoactive medications were used in the immediate perioperative period, after thoracoabdominal aortic aneurysm repair was completed and the aortic crossclamp was removed. Initiation of angiotensin II corresponded with a significant increase in mean arterial pressure and a reduction in the dosages of concomitant vasoactive medications. The units for each medication are shown in the key.

the celiac, superior mesenteric, and bilateral renal arteries with a multibranched graft (Gelweave Coselli Thoracoabdominal Graft; Terumo Aortic, Ann Arbor, Mich). Left heart bypass time was 32 minutes, and the total transfusion requirements included 8 units of packed red blood cells, 4 units of fresh frozen plasma, 8 units of platelets, and 20 units of cryoprecipitate. Despite infusions of norepinephrine at $0.13 \mu \mathrm{g} / \mathrm{kg} / \mathrm{min}(10 \mu \mathrm{g} / \mathrm{min})$, high-dose vasopressin at $0.13 \mathrm{U} / \mathrm{min}(8 \mathrm{U} / \mathrm{h})$, epinephrine at $0.26 \mu \mathrm{g} / \mathrm{kg} / \mathrm{min}$ (20 $\mu \mathrm{g} / \mathrm{min}$ ), and dopamine at $5 \mu \mathrm{g} / \mathrm{kg} / \mathrm{min}$, the patient's MAP could not be sustained above the upper $60 \mathrm{~s} \mathrm{~mm} \mathrm{Hg}$ after the aortic crossclamp was removed. Once total vasopressor dosage reached the institutional threshold for initiation of AngII $(0.3 \mu \mathrm{g} / \mathrm{kg} / \mathrm{min}$ norepinephrine equivalents [NEE]), AngII was requested from the central pharmacy. By the time AngII administration was initiated in the operating room approximately 15 minutes later, the maximal medication doses reached were $0.7 \mu \mathrm{g} / \mathrm{kg} / \mathrm{min}$ NEE (Figure 1). After the MAP reached 80 to $90 \mathrm{~mm} \mathrm{Hg}$ within 5 minutes of starting AngII, we maintained the AngII at 60 to $80 \mathrm{ng} / \mathrm{kg} / \mathrm{min}$. When the patient arrived in the intensive care unit, identical vasopressor dosages were maintained except the epinephrine dosage, which was lowered to $0.13 \mu \mathrm{g} / \mathrm{kg} / \mathrm{min}(10 \mu \mathrm{g} / \mathrm{min})$. The cardiac output was $11 \mathrm{~L} / \mathrm{min}$, and systemic vascular resistance was 420 dynes $\bullet \cdot \mathrm{cm}^{-5}$. Methylene blue, low-dose glucocorticoids, thiamine, and ascorbic acid were also administered after the target MAP was reached with AngII. The hemoglobin level was maintained above $10 \mathrm{~g} / \mathrm{dL}$ during this period.

During the next 24 hours, AngII was continued at the same dose, whereas epinephrine and norepinephrine were reduced to $0.07 \mu \mathrm{g} / \mathrm{kg} / \mathrm{min}(5 \mu \mathrm{g} / \mathrm{min})$ and vasopressin to $0.04 \mathrm{U} / \mathrm{min}(2.5 \mathrm{U} / \mathrm{h})$. In the 24 hours after that, the AngII dosage was reduced to $20 \mathrm{ng} / \mathrm{kg} / \mathrm{min}$, epinephrine was stopped, and the patient was liberated from mechanical ventilation. AngII was stopped after 40 hours and the remaining vasopressors after 96 hours while MAP was maintained at 80 to $90 \mathrm{~mm} \mathrm{Hg}$ (Figure 1). Temporary continuous renal-replacement therapy for stage 3 acute kidney injury was initiated on postoperative day 2 and was continued for 1 week. When the patient demonstrated bilateral leg raising on postoperative day 3 , the cerebrospinal fluid drain was removed. After an 18-day postoperative course, the patient was discharged home ambulatory without signs of digital limb ischemia or deep venous thrombosis. 

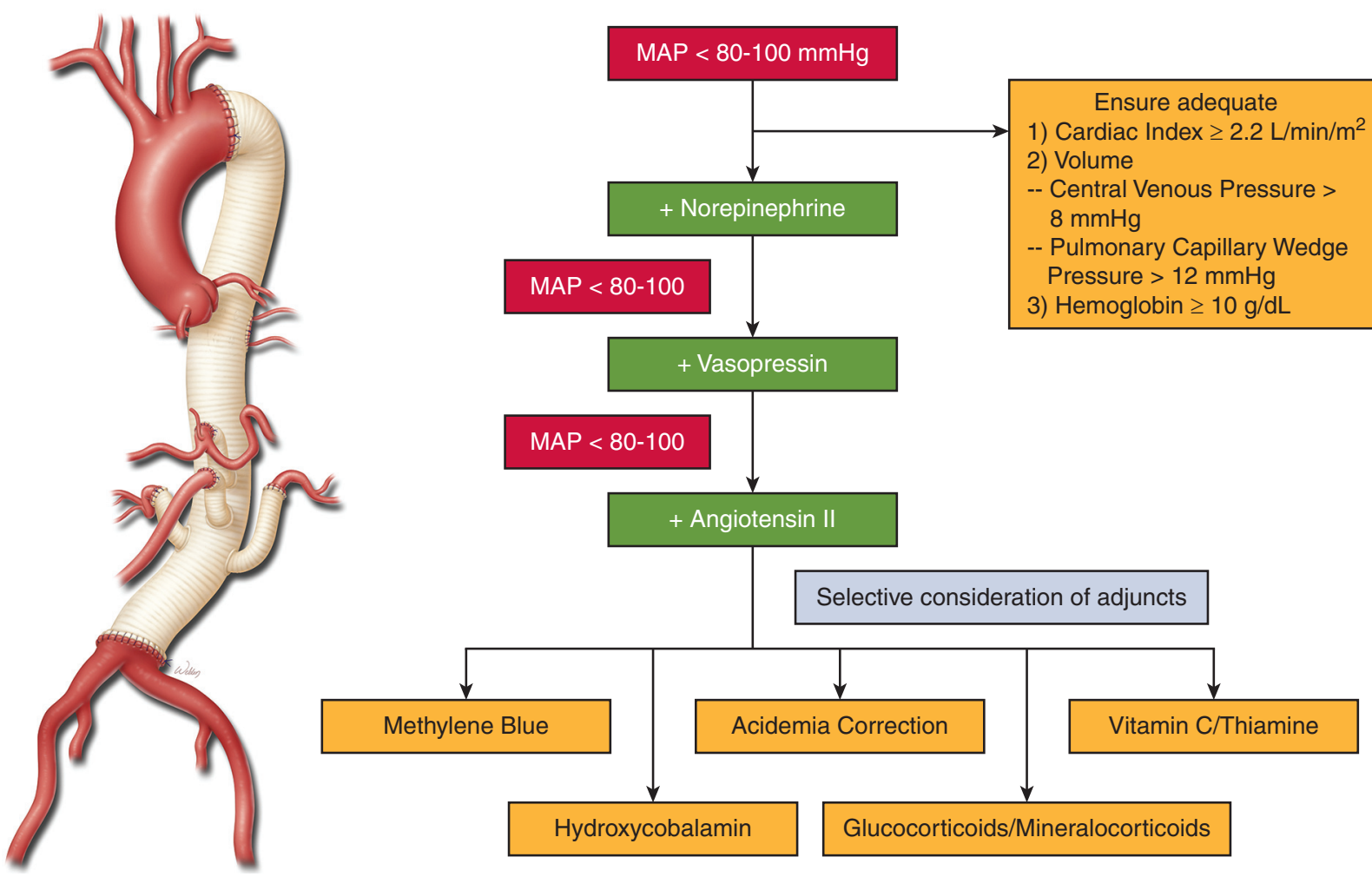

FIGURE 2. Vasoplegia management algorithm with vasopressors and selective use of adjuncts. MAP, Mean arterial pressure.

\section{DISCUSSION}

Vasoplegia after cardiac surgery has an incidence of 5\% to $45 \%$ and is associated with substantially elevated mortality risk. ${ }^{2}$ The standard management of vasoplegia includes treatment with vasopressors and other adjuncts (eg, methylene blue, hydroxocobalamin, vitamin $\mathrm{C}$, thiamine, glucocorticoids). ${ }^{3}$ Because AngII has been shown to raise $\mathrm{MAP}^{4,5}$ our institutional practice is to initiate AngII after cardiac surgery when vasopressors exceed an NEE of $0.3 \mu \mathrm{g} / \mathrm{kg} / \mathrm{min}$, or $0.4 \mu \mathrm{g} / \mathrm{kg} / \mathrm{min}$ if the patient has sepsis or cirrhosis. However, the safety and efficacy of administering AngII after TAAAR have not been described, to our knowledge. On the basis of our institutional experience with AngII, we promptly initiated AngII infusion in our patient to achieve a minimally acceptable MAP of $80 \mathrm{~mm} \mathrm{Hg}$. Despite restoration of a satisfactory MAP, the patient required temporary continuous renal-replacement therapy; however, the more severe, life-altering complication of SCD was avoided.

Strategies to prevent vasoplegia include preoperative discontinuation of renin-angiotensin-aldosterone system inhibitors, ${ }^{2}$ postoperative discontinuation of medications that exacerbate hypotension (eg, propofol), and transfusion to a target hemoglobin level of $10 \mathrm{~g} / \mathrm{dL}$ to improve oxygen delivery. Part of the diagnostic dilemma is that hypotension after TAAAR can also be related to a low cardiac output state, hypovolemia, or hemorrhage-all of which must be excluded. Our current vasoplegia management algorithm, including the escalation of vasopressors and use of adjuncts, is outlined in Figure 2. After a satisfactory MAP is achieved, selective use of adjuncts can be considered as a possible means of accelerating resolution of the vasoplegia process and weaning of all vasopressors (Video 1).

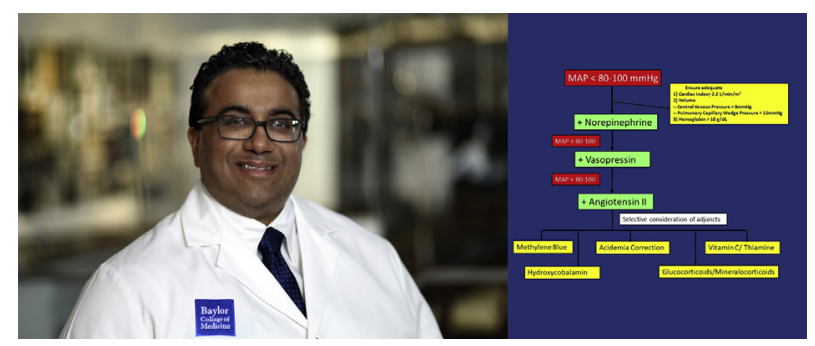

VIDEO 1. Dr Chatterjee discusses the importance and relevance of the case report and management of vasoplegia after thoracoabdominal aortic aneurysm repair. Video available at: https://www.jtcvs.org/article/S26662507(20)30382-5/fulltext. 
After our patient underwent TAAAR, we maintained a MAP of $80 \mathrm{~mm} \mathrm{Hg}$ and confirmed intact neurologic function before reducing the dose of AngII. We conclude that in cases of severe vasoplegia refractory to conventional vasopressors, AngII can be considered as an alternative option for achieving an adequate MAP while reducing SCD risk.

We appreciate the editorial support of The Department of Scientific Publications at the Texas Heart Institute and the graphic artwork of Scott Weldon, MA, CMI, FAMI, of the Division of Cardiothoracic Surgery at Baylor College of Medicine.

\section{References}

1. Coselli JS, LeMaire SA, Preventza O, de la Cruz KI, Cooley DA, Price MD, et al Outcomes of 3309 thoracoabdominal aortic aneurysm repairs. J Thorac Cardiovasc Surg. 2016;151:1323-37.

2. Shaefi S, Mittel A, Klick J, Evans A, Ivascu NS, Gutsche J, et al. Vasoplegia after cardiovascular procedures-pathophysiology and targeted therapy. J Cardiothorac Vasc Anesth. 2018;32:1013-22.

3. Jentzer JC, Vallabhajosyula S, Khanna AK, Chawla LS, Busse LW, Kashani KB Management of refractory vasodilatory shock. Chest. 2018;154:416-26.

4. Khanna A, English SW, Wang XS, Ham K, Tumlin J, Szerlip H, et al. Angiotensin II for the treatment of vasodilatory shock. $N$ Engl J Med. 2017;377:419-30.

5. Klijian A, Khanna AK, Reddy VS, Friedman B, Ortoleva J, Evans AS, et al. Treatment with angiotensin II is associated with rapid blood pressure response and vasopressor sparing in patients with vasoplegia after cardiac surgery: a post-hoc analysis of Angiotensin II for the Treatment of High-Output Shock (ATHOS-3) study. J Cardiothorac Vasc Anesth. August 7, 2020 [Epub ahead of print]. 